\title{
International Trade and the Value of Time
}

\author{
Udayan Roy*
}

\begin{abstract}
I discuss a generalized Heckscher-Ohlin-Vanek (HOV) model in which consumption requires time as well as money (as in Becker's theory of the allocation of time) and the amount of work that a worker can do per unit of time-her "ability" - varies from country to country. High ability implies high income per hour, which implies a high value of time and, therefore, high consumption of the good that is more "time-saving." Therefore, if domestic production of this good is not commensurately high, it would have to be imported. In this way, I demonstrate that international differences in worker ability constitute an independent source of gains from trade. The model is able to explain several observed features of North-South trade that are not explained by the HOV model. The theoretical possibility of a Leontief paradox-type trade pattern is also demonstrated.
\end{abstract}

\section{Introduction}

Gary Becker's theory of the allocation of time has helped clarify our understanding of a long list of economic issues. In this paper, I argue that Becker's theory can strengthen our analysis of the pure theory of international trade as well. Specifically, I show that international differences in the value of time constitute an independent source of gains from trade. I generalize the Heckscher-Ohlin-Vanek (HOV) model by introducing the assumption that consumption requires time as well as money, as in Becker (1965), and by allowing worker ability-i.e. the amount of work that a worker can do per unit of time-to vary from country to country. The generalized model shows how the HOV model may be modified to fit reality better.

As was pointed out in Markusen (1986), the HOV model cannot explain (a) why the percentage of total consumer spending that goes to a particular good, such as food, is not the same in the rich countries (North) and the poor countries (South), and (b) why, despite large differences in capital-labor ratios, the volume of international trade between North and South is as low as it is. ${ }^{1}$

Consider the HOV description of North-South trade. North and South are assumed to be identical except that the per capita endowment of capital is higher in the North. As a result, North produces relatively more of the capital-intensive good. However, North does not consume relatively more of that good. In fact, the ratio of the amounts consumed of the capital- and labor-intensive goods is necessarily the same in North and South because preferences are assumed to be identical everywhere and homothetic. As a result, capital-abundant North exports the capital-intensive good to South, and labor-abundant South exports the labor-intensive good to North. The key source of gains from trade in HOV is, therefore, the difference in the per capita endowment of capital between North and South. There is a well-defined sense in which the bigger this difference is, the greater is the volume of trade predicted by HOV; see Helpman and Krugman (1985, sec. 1.5). The empirical problem with this scenario,

\footnotetext{
* Roy: Economics Department, Long Island University, Greenvale, NY 11548, USA. Tel: 516-299-2405; E-mail: uroy@liu.edu. I have benefited immensely from discussions with Jim Schmitz. He is not responsible, however, for this paper's shortcomings.
} 
however, is that North and South, despite large differences in their per capita endowments of capital, do not trade nearly as much as HOV predicts they would. Their production patterns do tend to differ, as suggested by HOV, but, contrary to HOV predictions, their consumption patterns tend to differ as well; see Markusen (1986), Hunter (1988), and Markusen et al. (1995, p. 197). North generally produces and consumes relatively more of the capital-intensive good, and South generally produces and consumes relatively more of the labor-intensive good. As a result of this congruence of each country's production and consumption patterns there is little need for trade.

How are we to explain this empirical failure of the HOV theory? This paper argues that the low level of North-South trade may in part be due to international variation in the value of time. Consumption is assumed to take time, following Becker (1965). I assume that the Northern worker can get more work done per unit of time than the Southern worker, and, given factor price equalization, has higher hourly earnings from labor. This in turn implies a higher opportunity cost of the time needed for consumption. Consequently, North spends a bigger share of its gross national product on the good that is the more "time-saving" (in a sense to be defined later) of the two. If the "time-saving" good also happens to be the capital-intensive good, then North will not only consume relatively more of the capital-intensive good (because North has a higher value of time), it will also produce relatively more of the capital-intensive good (because North has more capital per capita). Similarly, not only will the South consume relatively more of the labor-intensive good (because South has a lower value of time), it will also produce relatively more of the labor-intensive good (because South has less capital per capita). As a result, there will be little or no trade between the two. In this way, I explain (i) the low observed levels of North-South trade and (ii) the fact that North and South do not consume goods in the same proportions. (The reader may have noted an irony here. Two independent sources of trade-variations in relative factor endowments and variations in the value of time-are acting in concert to help explain the absence of trade between North and South.)

Markusen (1986) provided an explanation for these observed features of North-South trade by assuming a specific form of quasi-homothetic preferences. ${ }^{2} \mathrm{My}$ paper, by contrast, uses the twin assumptions of Becker's time constraint and international variations in worker ability. Becker's time constraint is widely used in economic analysis, especially in areas such as the theory of labor supply and the economics of fertility. And the addition of international variations in worker ability to the HOV model has already established a major presence in the trade literature; Trefler (1993) and Hakura (2001) have shown that the HOV prediction-that factor abundance predicts the direction of trade in the factor services that are embodied in the traded goods-becomes more reliable when productivity is allowed to vary across countries and resources are measured in productivity units.

In this paper, although preferences are identical and homothetic, consumption patterns vary from country to country because of differences in the opportunity cost of time, and not, as in Markusen (1986), because of differences in income. If there are two people with different levels of capital income, their consumption patterns would be the same under my assumptions, but different under Markusen's. In other words, these two sets of assumptions have empirically distinct implications.

Finally, it should be noted that Trefler (1995) tests several alternative hypotheses against HOV and concludes: "HOV is rejected in favor of a modification that allows for home bias in consumption and international technology differences." The international differences in worker ability in my paper are similar to Trefler's "international technology differences." And as for his "home bias in consumption," this paper's expla- 
nation for the low volume of North-South trade shows how home bias may arise out of the actions of utility-maximizing consumers. Moreover, this explanation for the home bias relies, in part, on international differences in worker ability. In other words, the two main features of the hypothesis that did best in Trefler's study are not only present in my model, they are integrally linked.

The key point of this paper is that international variations in the opportunity cost of time are a separate source of gains from trade. These differences derive in turn from international variations in worker ability and the assumption that consumption requires time.

Section 2 describes the model, section 3 discusses the main results, section 4 contains the proofs, and section 5 concludes the paper.

\section{The Basic Model of Trade}

This section describes a model of trade that is identical to the $2 \times 2 \times 2 \mathrm{HOV}$ model except that (i) consumers face a time constraint (as well as a budget constraint), and (ii) the ability of the representative worker varies from country to country.

There are two countries, $c=A, B$, two factors of production, $f=L, K$, called effective labor time (or labor, for short) and capital, and two consumer goods, $i=X, Y$. The technology for the production of $X$ is the same in both countries, as is the technology for the production of $Y$, and these production technologies are concave and obey constant returns to scale. All individuals, irrespective of citizenship, have the same homothetic and strictly quasi-concave preferences. Each individual is endowed with one unit of time. If an individual spends $e$ units of time at work, then $1-e$ units of time are spent at home for consumption. Time is necessary for consumption; $t_{i}$ is the time needed to consume one unit of good $i$. The population size of country $c$ is $N_{c}$. All $N_{c}$ citizens of country $c$ have the same ability, denoted $h_{c}$. A worker with ability $h_{c}$, working $e$ units of time, supplies $e h_{c}$, units of labor. (In other words, high-ability workers can provide more labor services per unit of time or can get more work done per unit of time than low-ability workers.) Individuals also own capital; $K_{c}$ denotes the total endowment of capital of country $c$. Labor and capital are immobile internationally. But trade in the final goods, $X$ and $Y$, is free. All markets are perfectly competitive.

Recall that the higher the value of $h_{c}$, the higher is the amount of labor services supplied by a citizen of country $c$ per unit of time she spends at work. Therefore, the higher the value of $h_{c}$, the higher is the opportunity cost of time devoted to consumption. It is for this reason that I will refer to international variations in worker ability as international variations in the opportunity cost of time or the value of time.

It will be assumed without loss of generality that the unit of account in which prices are expressed is the same in both countries. Therefore, under free trade, there will be one worldwide price $p_{x}$ for good $X$ and one worldwide price $p_{y}$ for good $Y$. Moreover, for the purposes of this paper, it will be necessary to discuss only free-trade equilibria in which factor prices are equalized as a result of trade in commodities. Therefore, we can let $w_{L}$ and $w_{K}$ denote factor prices in the two countries. In the rest of this paper, equilibrium will mean free-trade equilibrium with factor price equalization. (Conditions for factor price equalization will be discussed later.)

\section{Consumer Behavior}

Consider a citizen of country $c$ with ability $h_{c}$, and physical capital $k$. Let $x, y$, and $e$ denote, respectively, this individual's consumption of $X$, his consumption of $Y$, and the 
time he spends at work. Then, the consumer's choice problem is to choose $x, y$, and $e$ so as to maximize the quasi-concave and homothetic utility function $u(x, y)$ subject to the budget constraint $x p_{x}+y p_{y} \leq w_{L} e h_{c}+w_{K} k$, the time constraint $x t_{x}+y t_{y} \leq 1-e$, and the non-negativity constraints $x, y, e, 1-e \geq 0$. $^{3}$

I will assume that the optimal values of $x, y$, and $e$ are all strictly positive for all consumers. When that is the case, both constraints can be shown to be binding at the optimal values of $x, y$, and $e .^{4}$ Consequently, the consumer's choice problem can be restated as that of choosing $x$ and $y$ to maximize $u(x, y)$ subject to $x \cdot\left(p_{x}+w_{L} h_{c} t_{x}\right)+$ $y \cdot\left(p_{y}+w_{L} h_{c} t_{y}\right)=w_{L} h_{c}+w_{K} k$, which is a super-constraint obtained by combining the budget and time constraints. This super-constraint may be compactly written as $x P_{x c}+$ $y P_{y c}=w_{L} h_{c}+w_{K} k$, where $P_{i c} \equiv p_{i}+w_{L} h_{c} t_{i}, i=X, Y$, includes not only the price $p_{i}$ that one must pay to buy a unit of good $i$ but also $w_{L} h_{c} t_{i}$, which is the market value of the time that is necessary to consume that unit of good $i$. (From now on I will refer to $p_{i}$ as the worldwide accounting price of good $i$ and to $P_{i c}$ as the economic price of good $i$ in country $c$.)

This modified version of the consumer's maximization problem gives the first-order condition $u_{x}(x, y) / u_{y}(x, y)=P_{x c} / P_{y c}$, where $u_{x}(x, y)$ and $u_{y}(x, y)$ are, respectively, the partial derivatives of $u(\cdot, \cdot)$ with respect to $x$ and $y$. In other words, the first-order condition for utility maximization requires the marginal rate of substitution to be equal to the ratio of economic prices. As I have assumed that preferences are identical and homothetic, this first-order condition can be written in aggregate terms as

$$
\frac{u_{x}\left(X_{c}, Y_{c}\right)}{u_{y}\left(X_{c}, Y_{c}\right)}=\frac{P_{x c}}{P_{y c}},
$$

where $X_{c}$ is the total quantity demanded of good $X$ in country $c$, and $Y_{c}$ is defined analogously.

From the individual budget constraint, we get the aggregate budget constraint for country $c$ :

$$
X_{c} p_{x}+Y_{c} p_{y}=w_{L} L_{c}+w_{K} K_{c}
$$

where $L_{c}$ is the total labor supply for country $c$. The total time spent at work is then $L_{c} / h_{c}$ and the remaining time, $N_{c}-L_{c} / h_{c}$, is the total time spent on consumption. Consequently, from the individual time constraint, we get the aggregate time constraint for country $c$ :

$$
X_{c} t_{x}+Y_{c} t_{y}=N_{c}-\frac{L_{c}}{h_{c}} .
$$

Equations (2) and (3) then imply the aggregate super-constraint

$$
X_{c} P_{x c}+Y_{c} P_{y c}=w_{L} h_{c} N_{c}-w_{K} K_{c} .
$$

Note that $X_{c}, Y_{c}$, and $L_{c}$ may be solved, in terms of the variables that consumers treat as parameters, from equation (1) and any two of the equations (2)-(4). For example, $X_{c}$ and $Y_{c}$ can be determined from equations (1) and (4) and $L_{c}$ could then be obtained from either (2) or (3). The fact that $X_{c}$ and $Y_{c}$ can be determined from equations (1) and (4) yields the following result:

Lemma 1. Let the aggregate capital stock increase by $d K_{c}$ and let the population size increase by $d N_{c}$. If $w_{L} h_{c} d N_{c}+w_{K} d K_{c}=0$, then $X_{c}$ and $Y_{c}$ will not change-i.e. $d X_{c}=$ $d Y_{c}=0$ - and $L_{c}$ will increase by $d L_{c}=h_{c} d N_{c}$. 
This is because the stipulated changes in $K_{c}$ and $N_{c}$ leave equations (1) and (4) essentially unchanged.

Note that the economic price ratio $P_{x c} / P_{y c}$ will, in general, not be the same for the two countries if $h_{A} \neq h_{B}$. Specifically, it is straightforward to show that

$$
\frac{t_{x}}{p_{x}}\{\gtreqless\} \frac{t_{y}}{p_{y}} \Leftrightarrow \frac{\partial\left(P_{x c} / P_{y c}\right)}{\partial h_{c}}\{\gtreqless\} 0 .
$$

The quasi-concavity and homotheticity of the utility function then implies

$$
\frac{t_{x}}{p_{x}}\{\gtreqless\} \frac{t_{y}}{p_{y}} \Leftrightarrow \frac{\partial\left(X_{c} / Y_{c}\right)}{\partial h_{c}}\{\supseteqq\} 0 .
$$

Equation (5) indicates that international differences in $h_{c}$ may be able to explain international differences in $X_{c} / Y_{c}$. The amount of time needed to consume one dollar's worth of good $i$ is $t_{i} / p_{i}$. This ratio is a measure of how "time-saving" good $i$ is, and it plays an important role in determining consumer behavior. When $t_{x} / p_{x}=t_{y} / p_{y}, X$ and $Y$ are equally time-saving and the time and budget constraints, (2) and (3), are "parallel." Moreover, since (2) and (3) must be binding at $\left(Y_{c}, X_{c}\right)$, they are not just parallel, they actually coincide; in other words, Becker's time constraint fails to make a difference. If, on the other hand, $X$ and $Y$ are not equally time-saving, consumers with higher levels of human capital (and, therefore, higher opportunity costs for the time that is necessary for consumption) will, according to (5), consume relatively more of the good that is more time-saving. (It should be noted that $p_{x}$ and $p_{y}$ are endogenous variables, and that, therefore, it is not possible to say which good is more time-saving without working out the equilibrium values of $p_{x}$ and $p_{y}$.)

The consumer behavior that we see here can be easily related to some of the obvious differences between the typical First World household and the typical Third World household. Consider a food item that can be either (i) bought raw in ingredient form, prepared at home, and then consumed, or (ii) bought in fully cooked form and eaten straight out of a can. Becker's theory, as embodied in equation (5), gives us a way to explain international differences in the relative popularity of these two modes of consumption without requiring preferences to be either non-identical or non-homothetic.

\section{Market-clearing Conditions}

Concavity and constant returns in production plus perfect competition implies

$$
p_{i}=p_{i}\left(w_{K}, w_{L}\right)
$$

where $p_{i}\left(w_{K}, w_{L}\right)$ is the unit cost function for good $i$. Letting $a_{f}$ be the factor coeffcient or the amount of factor $f, f=K, L$, that is used in the manufacture one unit of good $i$, Shephard's lemma implies $a_{f}\left(w_{K}, w_{L}\right) \equiv \partial p_{i}\left(w_{K}, w_{L}\right) / \partial w_{f}$. Let $i_{c}^{S}$ be the quantity supplied of consumer $\operatorname{good} i$ in country $c$. Then $f_{c i}=a_{f} \cdot i_{c}^{S}$ is the quantity demanded of factor $f$ in industry $i$ of country $c$ and $f_{c}^{D} \equiv f_{c X}+f_{c Y}$ is total factor demand for factor $f$ in country $c$. The lack of international factor mobility implies that both countries must satisfy the factor market-clearing condition. This is the requirement that, for any factor $f$, the quantity demanded must be equal to the quantity supplied:

$$
f_{c}^{D} \equiv a_{f X} \cdot X_{c}^{S}+a_{f Y} \cdot Y_{c}^{S}=f_{c},
$$


for $f=K, L$ and $c=A, B$. Recall that, whereas $K_{c}$ is a known parameter, $L_{c}$ is an endogenous variable that will have to be solved for.

Finally, the worldwide market-clearing condition for consumer goods $X$ and $Y$ is

$$
X_{W}=X_{W}^{S} \quad \text { and } \quad Y_{W}=Y_{W}^{S},
$$

where $i_{W} \equiv i_{A}+i_{B}$ and $i_{W}^{S} \equiv i_{A}^{S}+i_{B}^{S}$ for $i=X, Y$.

Equations (1)-(3) and (6)-(8) can be used to solve for the equilibrium. ${ }^{5}$ As it is not possible to uniquely solve for all nominal prices, I will adopt the normalization $w_{K}=$ 1. Equation (6) then determines $p_{x}$ and $p_{y}$ in terms of $w_{L}$. Then equations (1)-(3) determine $X_{c}, Y_{c}$, and $L_{c}$ in terms of $w_{L}$. Equation (7) then solves for $X_{c}^{S}$ and $Y_{c}^{S}$, the supplies, in terms of $w_{L}$. Finally, equation (8), for either $\operatorname{good} X$ or $\operatorname{good} Y$, determines $w_{L}$. Once $w_{L}$ is determined, all the other unknowns, $X_{c}, Y_{c}, X_{c}^{S}, Y_{c}^{S}, L_{c}, p_{x}$, and $p_{y}$ can be determined from the other equations as was just indicated.

To ensure factor price equalization, the equilibrium values of the capital-labor ratios of the two countries must lie within the so-called "cone of diversification." Formally, the equilibrium values of $a_{f}\left(w_{K}=1, w_{L}\right)$ and $L_{c}$ obtained from equations (1)-(3) and (6)-(8) must also satisfy

$$
\min \left\{\frac{a_{K x}}{a_{L x}}, \frac{a_{K y}}{a_{L y}}\right\} \leq \frac{K_{c}}{L_{c}} \leq \max \left\{\frac{a_{K x}}{a_{L x}}, \frac{a_{K y}}{a_{L y}}\right\}
$$

for $c=A, B$.

To summarize, in equilibrium (or, more fully, free-trade equilibrium with factor price equalization) all agents act as price-taking maximizers, factor markets clear within each country, the worldwide goods markets are balanced, and the price of any commodityproduct or factor-is the same all over the world.

\section{Properties of Trade}

I will now discuss the properties of free-trade equilibrium under factor price equalization. The focus will be on the effects of international variations in the value of time on the pattern of comparative advantage. Proofs of results are given in the next section.

As is evident from (5), the HOV model can be obtained as a special case of this paper's model when $h_{A}=h_{B}$, because in this case the value of time does not vary internationally and the consumption ratio $X_{c} / Y_{c}$ is the same in both countries, as in HOV. However, there also exist non-HOV outcomes.

Let us define an indicator of relative factor abundance:

$$
V \equiv \operatorname{sign}\left(\frac{K_{A}}{L_{A}}-\frac{K_{B}}{L_{B}}\right) .
$$

As $L_{A}$ and $L_{B}$ are endogenously determined, so is $V$. Note that

$$
V=\left\{\begin{array}{l}
+ \\
0 \\
-
\end{array}\right\} \Leftrightarrow\left\{\begin{array}{c}
A^{\prime} \text { 's capital-labor ratio is higher than } B \text { 's } \\
A \text { and } B \text { have the same capital-labor ratio } \\
A \text { 's capital-labor ratio is lower than } B \text { 's }
\end{array}\right\} .
$$

Recalling that $K_{c}^{D} / L_{c}^{D}$ is the ratio of factor demands, note that balanced trade between countries $A$ and $B$ implies that $K_{A} / L_{A}-K_{A}^{D} / L_{A}^{D}$ and $K_{B} / L_{B}-K_{B}^{D} / L_{B}^{D}$ must have opposite signs. Therefore, I can define an indicator of the direction of trade in factor intensities as 


$$
U \equiv \operatorname{sign}\left(\frac{K_{A}}{L_{A}}-\frac{K_{A}^{D}}{L_{A}^{D}}\right)=\operatorname{sign}\left(\frac{K_{B}^{D}}{L_{B}^{D}}-\frac{K_{B}}{L_{B}}\right) .
$$

It follows that

$$
U=\left\{\begin{array}{c}
+ \\
0 \\
-
\end{array}\right\} \Leftrightarrow\left\{\begin{array}{c}
A \text { is exporting the capital-intensive good to } B \\
\text { No trade } \\
A \text { is exporting the labor-intensive good to } B
\end{array}\right\} .
$$

Under HOV assumptions, we always get $U=V$; that is, the factor content of a country's trade must reflect its relative factor abundance. Whether this prediction of the HOV model is robust to the introduction of (i) the Becker time constraint in the consumer's choice problem and (ii) international differences in labor ability is the subject of Theorem 1 below.

Theorem 1. Let $z \equiv\left(N_{A}, N_{B}, K_{A}, K_{B}, h_{A}, h_{B}\right)$ denote a world consisting of countries $A$ and $B$. Then, for any $\bar{U} \in\{+, 0,-\}$ and any $\bar{V} \in\{+, 0,-\}$, there exist $z$ such that $U=\bar{U}$ and $V=\bar{V}$ in equilibrium.

In other words, one can no longer look at national capital-labor ratios and deduce the pattern of trade or even whether there would be trade. For instance, while, by the HOV theory, $U$ would have to be $(+)$ if $V=(+)$, my generalized model allows $U=(0)$ or even $U=(-)$. That is, if two countries have different capital-labor ratios, the capitalabundant country might export the capital-intensive good (as in HOV), or there might be little or no trade at all despite the differences in relative factor abundances (as is the case with North-South trade), or the capital-abundant country might export the labor-intensive good (as in the Leontief paradox trade pattern). In other words, the empirically observed lack of correlation between factor abundance and the direction of trade in factor services is explained by this paper's generalization of HOV.

Further, Theorem 1 implies that there exist $z$ such that $V=0$ and $U \neq 0$ in equilibrium. In other words, in my generalized HOV model there can be trade even if both countries have the same capital-labor ratio. This underscores the point that international differences in the value of time are an independent source of gains from trade that can generate trade even if capital-labor ratios are equal.

Note also that $V=0$ and $U \neq 0$ implies that $K_{A}^{D} / L_{A}^{D} \neq K_{B}^{D} / L_{B}^{D}$. For $K_{A}^{D} / L_{A}^{D} \neq K_{B}^{D} / L_{B}^{D}$ to be true $X_{A} / Y_{A} \neq X_{B} / Y_{B}$ must also be true. This is significant because such international variation in consumption patterns is not possible under the HOV assumptions of identical and homothetic preferences. Also, to see why trade occurs in this case, note that $V=0$ or $K_{A} / L_{A}=K_{B} / L_{B}$ implies, by Rybczynski's theorem, that the ratios of the outputs of the two goods must be the same in the two countries; that is, $X_{A}^{S} / Y_{A}^{S}=X_{B}^{S} / Y_{B}^{S}$. The mismatch between the production and consumption patterns - that is, the coexistence of $X_{A} / Y_{A} \neq X_{B} / Y_{B}$ on the demand side with $X_{A}^{S} / Y_{A}^{S}=X_{B}^{S} / Y_{B}^{S}$ on the supply side-makes trade inevitable. (In HOV, on the other hand, trade occurs because $X_{A} / Y_{A}=X_{B} / Y_{B}$ on the demand side with $X_{A}^{S} / Y_{A}^{S} \neq X_{B}^{S} / Y_{B}^{S}$ on the supply side.)

Theorem 1 also implies the existence, in my generalized HOV model, of $z$ such that $V \neq 0$ and $U=0$ in equilibrium. This case implies that differences in capital-labor ratios are not only not necessary for trade to occur, they are not sufficient either. In this case $K_{A} / L_{A}=K_{A}^{D} / L_{A}^{D} \neq K_{B}^{D} / L_{B}^{D}=K_{B} / L_{B}$; that is, one country produces and consumes the capital-intensive good while the other country produces and consumes the laborintensive good. This outcome, while actually typical of North-South trade-see 
Markusen (1986) - is impossible under HOV assumptions. In the HOV model, the only source of comparative advantage is the international variation in capital-labor ratios and, as there is a vast difference in the capital-labor ratios of rich and poor countries, the HOV model predicts - contrary to fact - that trade between rich and poor countries should be especially vigorous.

Equilibria such that $V \neq 0$ and $U=0$ are interesting for yet another reason. Note that $V \neq 0$ implies $K_{A} / L_{A} \neq K_{B} / L_{B}$ and $U=0$ implies that, although trade is allowed, no trade occurs. The question then is: Why? After all, labor ought to be cheap in the laborabundant country. So why isn't that country exporting the labor-intensive good? The answer is that in this case not only is labor relatively abundant in this country, the demand for the labor-intensive good and, therefore, the (derived) demand for labor is also relatively high. This is the reason why autarky relative factor prices are the same in the two countries in spite of (possibly large) differences in their capital-labor ratios.

Finally, note that while the $V=U$ case is the HOV case, my model's $V=-U \neq 0$ case may be called the Leontief paradox case because in this scenario the capital-rich country exports the labor-intensive good and vice versa; see Leontief (1953) and Trefler (1993). Consider the country that has the higher capital-labor ratio in equilibrium. Suppose this country also has the higher level of worker ability and, therefore, has relatively heavy demand for the more "time-saving" of the two goods. Suppose, moreover, that this more "time-saving" good is also the capital-intensive good. In this case, this country, despite having the higher capital-labor ratio, might be driven by its great hunger for the capital-intensive good to import the capital-intensive good from the labor-abundant country. And, as is implied by balanced trade, the other country, despite having the higher labor-capital ratio, would import the labor-intensive good from the capital-abundant country.

\section{Proof of Theorem 1}

Let the value of a variable in the equilibrium of the two-country world $z$ be denoted by the symbol for that variable followed by $z$ in parentheses; e.g. let $w_{L}(z)$ and $w_{K}(z)=1$ denote the normalized equilibrium factor prices for $z$.

Figure 1 shows an Edgeworth box representing the equilibrium of $z$. The box's dimensions are $K_{W}=K_{A}+K_{B}$ and $L_{W}(z)=L_{A}(z)+L_{B}(z){ }^{6}$

Let $f_{W i}(z)=a_{f i}(z) \cdot i_{W}^{S}(z)$ be the amount of resource $f, f=K, L$, used in the equilibrium for the worldwide production of $i_{W}^{S}(z)$ units of $\operatorname{good} i, i=X, Y$, and let the vector $V_{i}(z)=\left(K_{W i}(z), L_{W i}(z)\right), i=X, Y$. Let $V_{c}^{D}(z)=\left(K_{c}^{D}(z), L_{c}^{D}(z)\right)$ denote the equilibrium factor demands of country $c$. Note that $\Sigma_{i} V_{i}(z) \equiv \Sigma_{c} V_{c}^{D}(z)$. Also, let $V_{c}^{S}(z)=\left(K_{c}, L_{c}(z)\right)$ denote the equilibrium factor supplies of country $c$.

In equilibrium we must have $\Sigma_{i} V_{i}(z)=\Sigma_{c} V_{c}^{D}(z)=\Sigma_{c} V_{c}^{S}(z)=\left(K_{W}, L_{W}(z)\right)$, the dimensions of the Edgeworth box. Therefore, one can find points $Q$ and $\bar{Q}$ in Figure 1 such that $O_{A} Q=O_{B} \bar{Q}=V_{y}(z)$ and $O_{B} Q=O_{A} \bar{Q}=V_{x}(z)$. One can find a point $D$ in the box such that $O_{c} D=V_{c}^{D}(z), c=A, B$. And one can find a point $S$ in the box such that $V_{c}^{S}(z)$ $=O_{c} S, c=A, B$. The directed line segments $D S$ and $S D$ would then represent $V_{A}^{D}(z)-$ $V_{A}^{S}(z)$ and $V_{B}^{D}(z)-V_{B}^{S}(z)$, the net factor imports of countries $A$ and $B$ respectively. (Note that Figure 1 places $Q$ and $\bar{Q}$ above and below the diagonal, respectively. This reflects the assumption-made without any loss of generality and for Figure 1 onlythat $Y$ is the capital-intensive good.)

At this point one cannot be specific about the location of $D$ and $S$ in the box. However, since strict quasi-concavity of the utility function implies that every consumer will consume positive amounts of both $X$ and $Y, D$, which represents the factor 


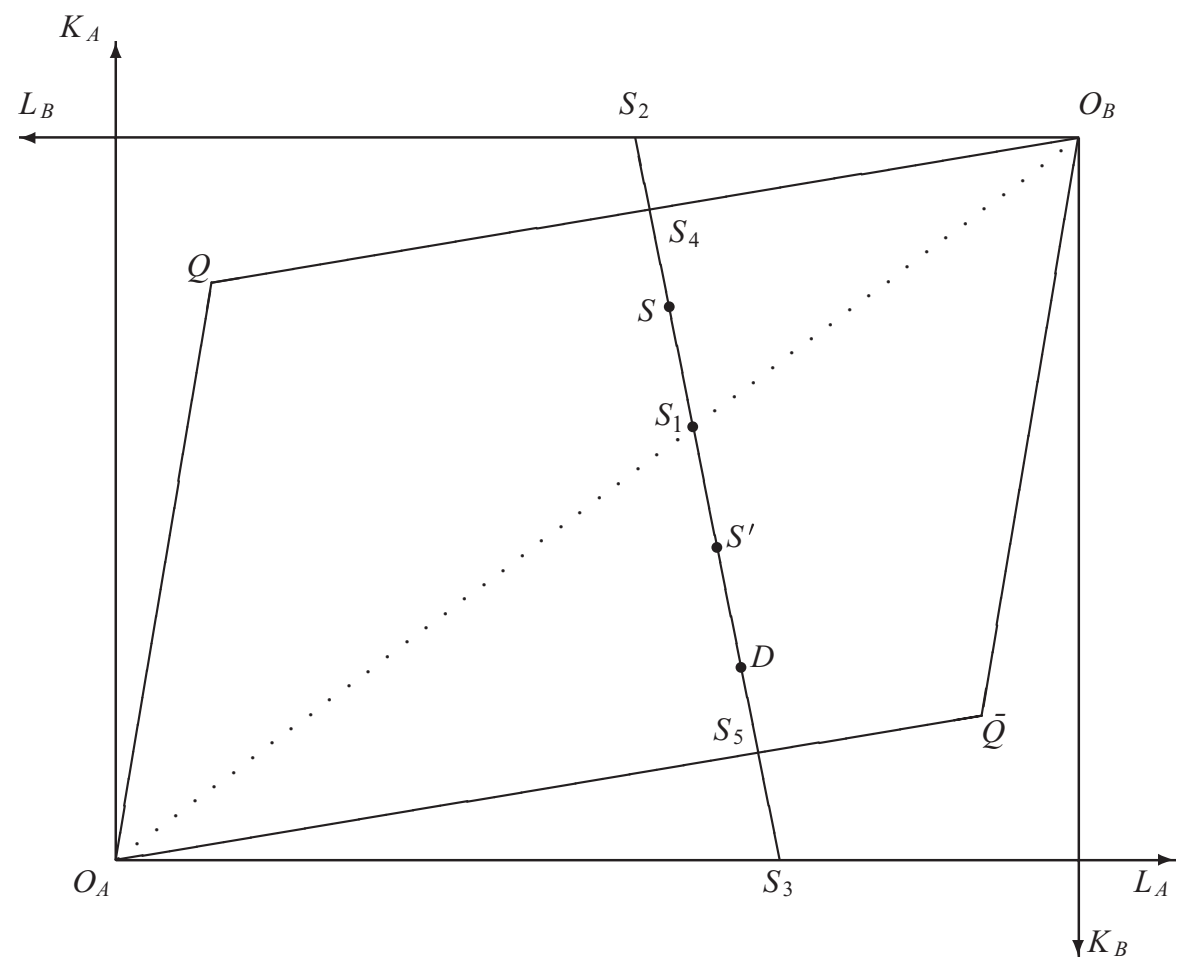

Figure 1. Trade with Factor Price Equalization

demands or the factor content of the equilibrium consumptions of $X$ and $Y$, must lie within the parallelogram $O_{A} Q O_{B} \bar{Q}$, as shown. Also, the budget constraint (2) implies that the market value of goods demands-in factor content terms-must equal the market value of factor supplies. Therefore, $S$ must be on the line through $D$ that has slope $-w_{L}(z) / w_{K}(z)\left[=-w_{L}(z)\right.$ since $w_{K}=1$ has been assumed]. This line is denoted $S_{2} S_{3}$ in Figure 1.

Let $\beta(z)=\left\{\left(\kappa_{A}, \lambda_{A}, \kappa_{B}, \lambda_{B}\right) \in \mathbf{R}_{++}^{4}\right.$ such that

$$
\begin{aligned}
& \kappa_{A}+\kappa_{B}=K_{A}+K_{B} \equiv K_{W}, \\
& w_{K}(z) \kappa_{c}+w_{L}(z) \lambda_{c}=w_{K}(z) K_{c}+w_{L}(z) L_{c}(z),
\end{aligned}
$$

for $c=A, B\}$, and let $\beta^{*}(z)=\left\{\left(\kappa_{A}, \lambda_{A}, \kappa_{B}, \lambda_{B}\right) \in \beta(z)\right.$ such that

$$
\min \left\{\frac{a_{K x}(z)}{a_{L x}(z)}, \frac{a_{K y}(z)}{a_{L y}(z)}\right\} \leq \frac{\kappa_{c}}{\lambda_{c}} \leq \max \left\{\frac{a_{K x}(z)}{a_{L x}(z)}, \frac{a_{K y}(z)}{a_{L y}(z)}\right\},
$$

$c=A, B\}$. In other words, $\beta(z)$ is the line segment $S_{2} S_{3}$ in Figure 1 and $\beta^{*}(z)$ is the line segment $S_{4} S_{5}$. Take any point on $S_{4} S_{5}$ and call it $S^{\prime}$. Let $O_{A} S^{\prime}=\left(K_{A}^{\prime}, L_{A}^{\prime}\right)$ and $O_{B} S^{\prime}=\left(K_{B}^{\prime}\right.$, $\left.L_{B}^{\prime}\right)$ define $K_{A}^{\prime}, L_{A}^{\prime}, K_{B}^{\prime}$, and $L_{B}^{\prime}$. Equivalently, choose $\left(K_{A}^{\prime}, L_{A}^{\prime}, K_{B}^{\prime}, L_{B}^{\prime}\right) \in \beta^{*}(z)$.

Now construct a new two-country world $z^{\prime}=\left(N_{A}^{\prime}, N_{B}^{\prime}, K_{A}^{\prime}, K_{B}^{\prime}, h_{A}^{\prime}, h_{B}^{\prime}\right)$, where $K_{A}^{\prime}$ and $K_{B}^{\prime}$ have already been defined, and

$$
\begin{aligned}
& h_{c}^{\prime}=h_{c}, \\
& N_{c}^{\prime}=N_{c}+\frac{L_{c}^{\prime}-L_{c}(z)}{h_{c}} .
\end{aligned}
$$


It turns out that the free-trade equilibrium for $z^{\prime}$ is identical to that for $z$ except that factor supplies are represented by $S$ for $z$, as we saw earlier, and by $S^{\prime}$ for $z^{\prime}$; everything else is the same. Formally,

Lemma 2. If, without loss of generality, we assume the normalization $w_{K}\left(z^{\prime}\right)=1$, then $w_{L}\left(z^{\prime}\right)=w_{L}(z), p_{i}\left(z^{\prime}\right)=p_{i}(z), X_{c}\left(z^{\prime}\right)=X_{c}(z), Y_{c}\left(z^{\prime}\right)=Y_{c}(z)$, and $L_{c}\left(z^{\prime}\right)=L_{c}^{\prime}$ for $i=X$, $Y$ and $c=A, B$. It follows that $f_{c}^{D}\left(z^{\prime}\right)=f_{c}^{D}(z)$ for $f=K, L$ and $c=A, B$.

Proof. Assume $w_{K}\left(z^{\prime}\right)=1$ and $w_{L}\left(z^{\prime}\right)=w_{L}(z)$. It follows from (6) that $p_{i}\left(z^{\prime}\right)=p_{i}(z)$. Then note, from the definition of $z^{\prime}$ and equations (11) and (14), that $w_{K}(z)$. $\left(K_{c}^{\prime}-K_{c}\right)+w_{L}(z) h_{c} \cdot\left(N_{c}^{\prime}-N_{c}\right)=0$. Therefore, Lemma 1 can be applied with the substitutions $d K_{c}=K_{c}^{\prime}-K_{c}$ and $d N_{c}=N_{c}^{\prime}-N_{c}$. It follows that if $w_{K}\left(z^{\prime}\right)=w_{K}(z)=1$ and $w_{L}\left(z^{\prime}\right)=w_{L}(z)$, then $X_{c}\left(z^{\prime}\right)=X_{c}(z), Y_{c}\left(z^{\prime}\right)=Y_{c}(z)$, and

$$
L_{c}\left(z^{\prime}\right)=L_{c}(z)+h_{c} \cdot \frac{L_{c}^{\prime}-L_{c}(z)}{h_{c}}=L_{c}^{\prime} .
$$

It follows that $K_{A}^{\prime}+K_{B}^{\prime}=K_{A}+K_{B}=K_{W}$ and $L_{A}\left(z^{\prime}\right)+L_{B}\left(z^{\prime}\right)=L_{A}^{\prime}+L_{B}^{\prime}=L_{W}(z)$. Therefore, we see that if the factor and commodity prices that prevailed in the equilibrium for $z$ continue to prevail in $z^{\prime}$, factor supplies would be unchanged in both countries and, since each country's (and, therefore, the world's) consumption of the goods $X$ and $Y$ are unchanged, worldwide factor demands for the production of $X$ and $Y$ would be unchanged. Therefore, all markets would clear as before. Therefore, the equilibrium factor and commodity prices for $z$ are, as was assumed at the beginning of this proof, also the equilibrium factor and commodity prices for $z^{\prime}$.

Moreover, since all prices are the same in $z^{\prime}$ and $z$, the factor coefficients must also be the same: $a_{f i}\left(z^{\prime}\right)=a_{f i}(z)$. And since $X_{c}\left(z^{\prime}\right)=X_{c}(z)$ and $Y_{c}\left(z^{\prime}\right)=Y_{c}(z)$, the factor demands must also be the same in the two cases: $f_{c}^{D}\left(z^{\prime}\right)=\sum_{i=X, Y} a_{f i}\left(z^{\prime}\right) \cdot i_{c}\left(z^{\prime}\right)=f_{c}^{D}(z)$ for $f=K, L$ and $c=A, B$.

Recall that Figure 1 shows, in an Edgeworth box, the equilibrium of $z$. In particular, its dimensions are $K_{A}+K_{B}=K_{W}$ and $L_{A}(z)+L_{B}(z)=L_{W}(z) ; D$ represents the factor content of the amounts of $X$ and $Y$ consumed in the countries $A$ and $B$; and $S$ represents the factor supplies in $A$ and $B$. As for $z^{\prime}, K_{A}^{\prime}+K_{B}^{\prime}=K_{W}$ and $L_{A}\left(z^{\prime}\right)+L_{B}\left(z^{\prime}\right)=$ $L_{W}(z)$. Therefore, its Edgeworth box has the same dimensions as the one in Figure 1. Moreover, since $f_{c}^{D}\left(z^{\prime}\right)=f_{c}^{D}(z), D$ represents the factor demands for both $z$ and $z^{\prime}$. The only change is in the representation of factor supplies: whereas $S$ represented equilibrium factor supplies for $z, S^{\prime}$ serves that purpose for $z^{\prime}$.

Recall that $S^{\prime}$ was picked at random from $S_{4} S_{5}$. Therefore, Lemma 2 proves that if we start with the Edgeworth box representation in Figure 1 of the equilibrium of $z$ and choose any arbitrary point on $S_{4} S_{5}$, it is possible to construct a two-country world $z^{\prime}$ such that the Edgeworth box representing its equilibrium is the same as that for $z$ except that equilibrium factor supplies are now represented by the chosen point.

The proof of Theorem 1 follows directly from Lemmas 2 and 3. The off-thediagonal position of $D$ in Figure 1 can be justified by Lemma 3, which is proved in an appendix. By Lemma 2 one can construct $z^{\prime}$ such that factor demands are at $D$ and factor supplies are also at $D$. Therefore, for this $z^{\prime}, V=(-)$ and $U=0$. Similarly, one can construct $z^{\prime}$ such that factor demands are at $D$ and factor supplies are at some point in the interior of $D S_{5}$ (that is, any point on $D S_{5}$ other than $D$ and $S_{5}$ ). In this case $V=U=(-)$. One can construct $z^{\prime}$ such that factor demands are at $D$ and factor 


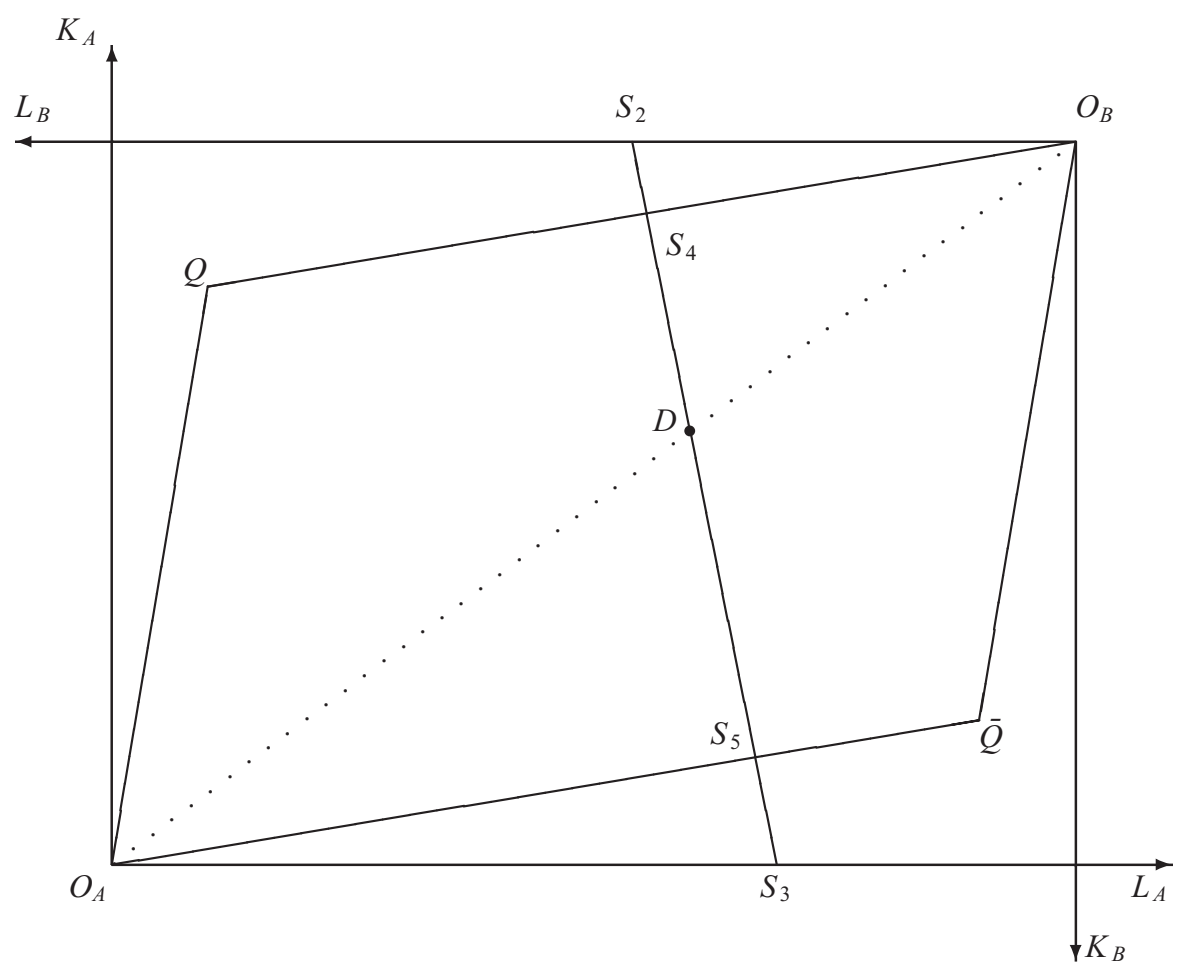

Figure 2. Trade with Factor Price Equalization: $h_{A}=h_{B}$, HOV Case

supplies are at some point in the interior of $D S_{1}$, to get a $z^{\prime}$ such that $V=(-)$ and $U=(+)$. One can construct $z^{\prime}$ such that the factor demands are at $D$ and factor supplies are at $S_{1}$ to get the $V=0$ and $U=(+)$ case, and one can construct $z^{\prime}$ such that the factor demands are at $D$ and factor supplies are at some point in the interior of $S_{1} S_{4}$, to get the $V=U=(+)$ case.

Moreover, by simply renaming country $A$ as country $B$ and country $B$ as country $A$, one can generate all the other cases except the $V=U=0$ case. To show that an example can be created that is consistent with this last case, assume that $z$ is such that $h_{A}=h_{B}$, making this the HOV special case. Now $D$ will necessarily be on the diagonal of the Edgeworth box for $z$-see Figure 2. Then, appealing again to Lemma 2, one can construct $z^{\prime}$ such that the factor demands are at $D$, on the diagonal, and factor supplies are also at $D$. Therefore, $U=V=0$ for this $z^{\prime}$, and the proof of Theorem 1 is complete.

\section{Conclusion}

The pure theory of international trade has highlighted several factors that can plausibly be said to be the sources of gains from trade. These include international differences in relative factor endowments, differences in technology, differences in government policies, increasing returns to scale, and imperfect competition. This paper has argued that differences in the value of time can also be a source of gains from trade.

The main theme of this paper has been that the empirical failures of the HeckscherOhlin-Vanek theory are best dealt with, not by denying the importance of relative 
factor endowments, but by taking note of the importance of the opportunity cost of time in the determination of demand patterns.

\section{Appendix: Proof of Lemma 3}

Lemma 3 merely says that $t_{x} / p_{x}(z)$ and $t_{y} / p_{y}(z)$ are not equal for all $z$ and all $\left(t_{x}, t_{y}\right)$.

Lemma 3. There exist $z$ and $\left(t_{x}, t_{y}\right)$ such that $h_{A} \neq h_{B}$ and $t_{x} / p_{x}(z) \neq t_{y} / p_{y}(z)$.

Proof. Take a $z$ and $\left(t_{x}, t_{y}\right)$ such that $h_{A} \neq h_{B}$. Suppose, contrary to the statement of this lemma, that $t_{x} / p_{x}(z)=t_{y} / p_{y}(z)$. Let $w_{K}(z)=1$ by normalization, and let $w_{L}(z)=$ $\tilde{w}_{L}$. Let $p_{i}(z)=\tilde{p}_{i}, i=X, Y$, and let $a_{l i}\left(w_{L}, w_{K}=1\right)=\tilde{a}_{l i}, i=X, Y$ and $l=K, L$. Then the integrated-equilibrium conditions for $z$ can be written as

$$
\begin{aligned}
& \frac{u_{x}\left(X_{c}, Y_{c}\right)}{u_{y}\left(X_{c}, Y_{c}\right)}=\frac{\tilde{p}_{x}+\tilde{w}_{L} h_{c} t_{x}}{\tilde{p}_{y}+\tilde{w}_{L} h_{c} t_{y}} \\
& X_{c} \cdot\left(\tilde{p}_{x}+\tilde{w}_{L} h_{c} t_{x}\right)+Y_{c} \cdot\left(\tilde{p}_{y}+\tilde{w}_{L} h_{c} t_{y}\right)=\tilde{w}_{L} h_{c} N_{c}+K_{c},
\end{aligned}
$$

for $c=A, B$, and

$$
\tilde{a}_{K x} \cdot X_{W}+\tilde{a}_{K y} \cdot Y_{W}=K_{W} .
$$

Let us change $t_{x}$ by an infinitesimal amount to $t_{x}^{\prime}$. Then, let us consider any one of the parameters $K_{A}, K_{B}, N_{A}$, and $N_{B}$-say, $K_{A}$-as an unknown, and then solve the displayed equations above, which represent the integrated equilibrium conditions, for the five unknowns $X_{c}, Y_{c}, c=A, B$, and $K_{A}$. If non-negative solutions are found-that will be the case, by continuity, if $X_{c}(z), Y_{c}(z)$, and $K_{A}$ were strictly positive to begin withthen we have a new $z$, say $\tilde{z}$, that differs from $z$ only in the value of $K_{A}$, such that $w_{K}(\tilde{z})=1, w_{L}(\tilde{z})=\tilde{w}_{L}, p_{x}(\tilde{z})=\tilde{p}_{x}$, and $p_{y}(\tilde{z})=\tilde{p}_{y}$. Note that $t_{x}^{\prime} / p_{x}(\tilde{z}) \neq t_{y}^{\prime} / p_{y}(\tilde{z})$, which completes the proof.

Note that the constructive method of proof used above can be used to construct examples for all combinations of $h_{A}>(<) h_{B}$ and $t_{x} / p_{x}(z)>(<) t_{y} / p_{y}(z)$.

\section{References}

Becker, Gary S., "A Theory of the Allocation of Time," Economic Journal 75 (1965):493-517.

Chen, Zhiqi, "The Heckscher-Ohlin Theorem with Endogenous Labour Supply," Bulletin of Economic Research 47 (1995):275-83.

Falvey, Rodney E. and Henryk Kierzkowski, "Product Quality, Intra-industry Trade and (Im)perfect Competition," in Henryk Kierzkowski (ed.), Protection and Competition in International Trade: Essays in Honor of W. M. Corden, Oxford: Basil Blackwell (1987):143-61.

Hakura, Dalia S., "Why does HOV Fail? The Role of Technological Differences within the EC," Journal of International Economics 54 (2001):361-82.

Helpman, Elhanan and Paul R. Krugman, Market Structure and Foreign Trade, Cambridge, MA: MIT Press (1985).

Hunter, Linda C., "The Contribution of Nonhomothetic Preferences to Trade," research paper 8809, Federal Reserve Bank of Dallas (November 1988).

Leontief, Wassily W., "Domestic Production and Foreign Trade: the American Capital Position Re-examined," Proceedings of the American Philosophical Society 97 (1953):332-49.

Markusen, James R., "Explaining the Volume of Trade: an Eclectic Approach," American Economic Review 76 (1986):1002-11. 
Markusen, James R., James R. Melvin, William H. Kaempfer, and Keith E. Maskus, International Trade: Theory and Evidence, New York: McGraw-Hill (1995).

Trefler, Daniel, “International Factor Price Differences: Leontief was Right!” Journal of Political Economy 101 (1993):961-87.

, "The Case of the Missing Trade and Other Mysteries," American Economic Review 85 (1995):1029-46.

Trefler, Daniel and Susan C. Zhu, "Beyond the Algebra of Explanation: HOV for the Technology Age," working paper, University of Toronto (2000).

\section{Notes}

1. The low volume of North-South trade is part of a deeper problem that confronts the HOV theory: the problem of "missing trade." See Trefler (1995) and Trefler and Zhu (2000).

2. Specifically, if $m(x, y)$ is the marginal rate of substitution, then it is assumed that $\partial m(\lambda \bar{x}, \lambda \bar{y}) / \partial \lambda$ must be either strictly positive for all $\lambda$ or strictly negative for all $\lambda$ at any $(\bar{x}, \bar{y})$. See also Falvey and Kierzkowski (1987) for a similar set of assumptions.

3. Note that the consumer's problem of allocation of time may also be seen as one of allocation of attention, or of involvement, or of effort. One can see the problem as that of allocating, at every instant in time, one's ability to concentrate, between the competing activities of work and enjoyment.

4. If $k$ is large enough, it may be best to choose $e=0$; that is, it may be best for a wealthy consumer to stay home all the time. In this case the time constraint would be binding, but the budget constraint would not.

5. Under the regularity assumptions of this paper, all equilibria will be unique.

6. Edgeworth boxes are generally used when both capital and labor are inelastically supplied. It will be shown here that the Edgeworth box analysis continues to be useful in this paper's model even though $L_{W}(z)$ is endogenously determined. My paper is related to the literature on the Heckscher-Ohlin model with endogenous labor supply—see Chen (1995) and the references therein. This literature introduces leisure in the utility function and leaves everything else in the HOV structure unchanged. It is assumed that leisure is a normal good and this implies that the country with the higher capital-population ratio will also have the higher capital-labor ratio and export the capital-intensive good just as in the HOV model. 